\title{
Study of Compound Heat Transfer Enhancement of Horizontal Liquid-Solid Fluidized Bed Heat Exchanger with a Kenics Static Mixer
}

\author{
Yan Liu ${ }^{1, \text { a }}$, Zhi Wang ${ }^{2, ~ a}$,Wei Zhang ${ }^{1, \text { b }}$,Chenglin $\mathrm{Pei}^{2, \text { a }}$ and Shaofeng Zhang ${ }^{1, \mathrm{c}}$ \\ ${ }^{1}$ School of Marine Science and Engineering, Hebei University of Technology, Tianjin, 300130, PR \\ China \\ ${ }^{2}$ Department of Chemical Engineering, Hebei University of Technology, Tianjin, 300130, PR China

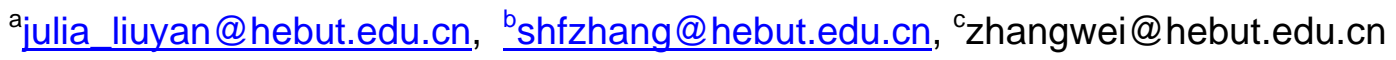

\begin{abstract}
Keywords: liquid-solid fluidized bed, heat exchanger, heat transfer enhancement, Kenics static mixer

Abstract. This paper describes the characteristics of heat transfer and pressure drop of the horizontal liquid-solid fluidized bed heat exchanger with a Kenics static mixer. The effects of inlet conditions of the working fluids and twist ratio on the heat transfer characteristics as well as pressure drop are discussed. The heat transfer rate and coefficient are the function of mass flow rate. The results show that the correlation between twist ratio and Reynolds number with respect to heat transfer enhancement is negative. Good agreement between the results obtained from the experiment and these obtained from the correlations is achieved.
\end{abstract}

\section{Introduction}

The high-performance heat exchangers can be obtained by heat transfer enhancement techniques. Enhancement techniques can be classied either as passive, which require no direct application of external power, or as active, which require external power. The liquid-solid fluidized bed heat exchanger usually consists of a vertical shell-and-tube configuration with a fluidized bed of steel, glass or ceramic particles in the tubes. The main advantages of fluidized bed heat exchangers are that they show high heat transfer coefficients and that the investment costs per unit of heat transfer area are low compared to scraped surface heat exchangers.

Substantial papers described the heat transfer enhancement and pressure drop in the tube with various inserts and liquid-solid fluidized bed heat exchanger. However, none of them discussed the heat transfer enhancement and pressure drop of liquid-solid fluidized bed heat exchanger with Kenics static mixers. In this paper, the heat transfer characteristics of horizontal liquid-solid fluidized bed were investigated by Kenics static mixer. Use of Kenics static mixer may be restricted by substantially pressure drop caused by helical elements, but it has been widely accepted in food and chemical industries. In addition, other parameters and twist ratio are also investigated. The saturated calcium sulfate solution whose Reynolds numbers are in the range of 14,000 to 45,000 was used as working fluid. Two types of results generated with and without Kenics static mixer were compared. The heat transfer enhancement and pressure loss as well as the empirical correlation for Nusselt number and friction factor were also analyzed and calculated.

\section{Experimental apparatus and method}

A schematic diagram of the experimental apparatus is shown in Fig. 1. The test loop consists of a test section, solid particles loop, liquid loop and data acquisition system. The test section was a liquid-solid fluidized heat exchanger that is shown in Fig. 2. The test section and the connections of the piping system were designed for the purpose of easy modification and repair. In order to measure and control the temperature and fluids flow rate, a set of sensors and controllers were installed. The test section was heated by winding electrical heater in order to provide a stable heat flux condition. The electrical power output was controlled by a variac transformer. The inlet and outlet temperatures of test tube as well as the surface temperature were measured by Six Pt-100 type thermocouples. The pressure drop was measured by a U-tube manometer that was placed across the test tube. 
The test tube was made of carbon steel, and its length (L) was $2000 \mathrm{~mm}$, inner diameter (D) was 27 $\mathrm{mm}$, outer diameter (Do) was $32 \mathrm{~mm}$, thickness (s) was $2.5 \mathrm{~mm}$. The Kenics static mixer was made of mild steel whose thickness $(\delta)$ was $2 \mathrm{~mm}$, width $(\mathrm{w})$ was $26 \mathrm{~mm}$, and twist ratios $(\mathrm{PR}=\mathrm{y} / \mathrm{w})$ was 1.5 , 2.0, 2.5, and 3.5 respectively. The twist ratio was defined as the ratio of two twist length $\left(\mathrm{y}, 180^{\circ}\right)$ to the tape width $(\mathrm{w})$.

Water volumetric flow rate varied from $0.62 \mathrm{~m} 3 / \mathrm{s}$ to $1.86 \mathrm{~m} 3 / \mathrm{s}$ which corresponded to Reynolds numbers ranging from 14,000 to 45,000 . The tested solid volume fractions were defined as $1 \%, 2 \%$, $3 \%$, and $4 \%$ respectively.

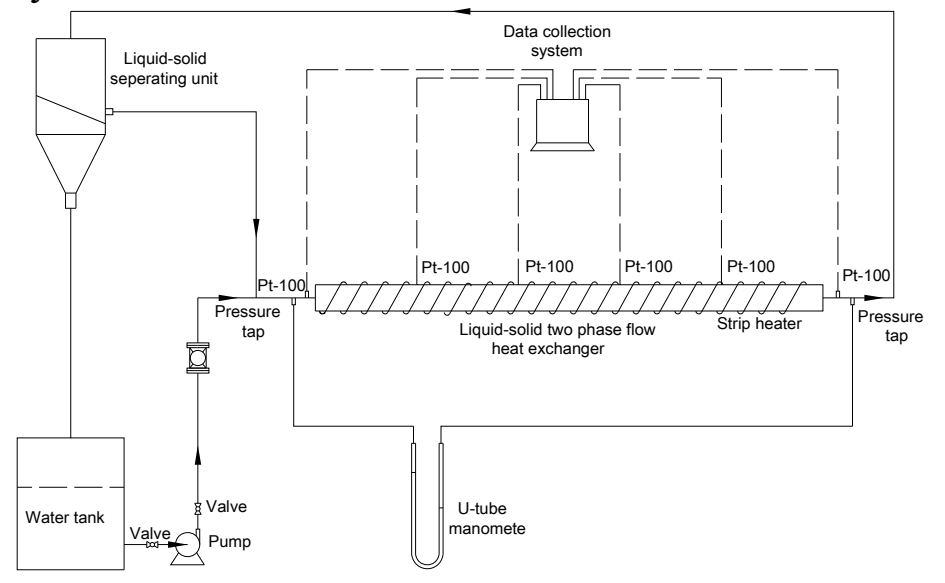

Fig.1. The schematic diagram of experimental apparatus.

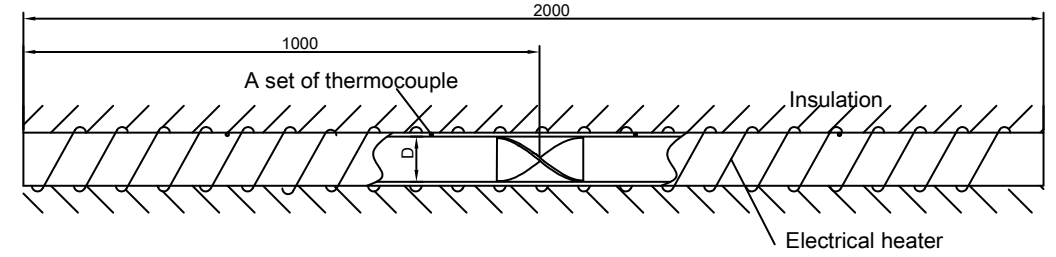

(a)

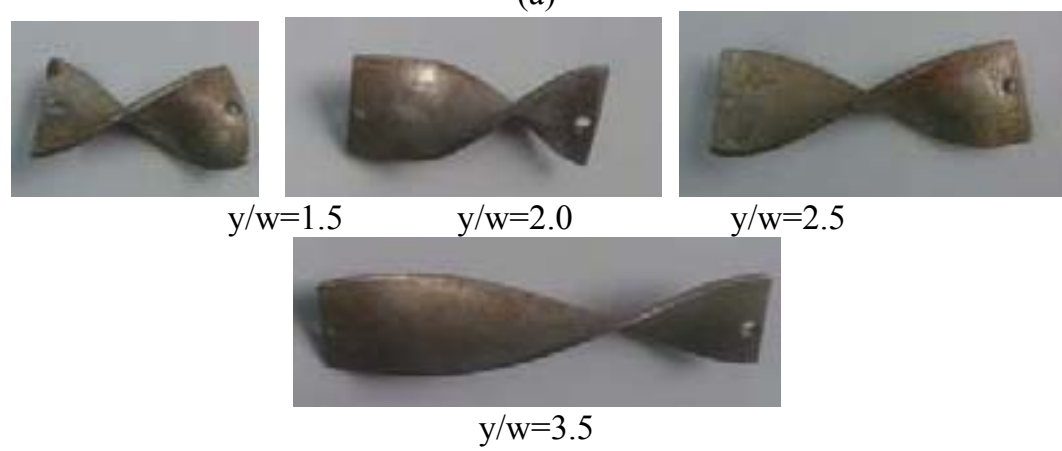

(b)

Fig.2. The test section with (a) location of thermocouples and Kenics static mixer and (b) various twist ratio Kenics static mixers.

\section{Data deduction}

The local heat transfer coefficient is defined in eq. 1 .

$$
\alpha=\frac{q}{\bar{T}_{w}-\bar{T}_{f}}
$$

Where $\bar{T}_{w}$ is surface temperature, $\bar{T}_{f}$ is local bulk temperature at the wall thermocouple location by following equations, i.e. eq. 2 , eq. 3 and eq. 4 , they also indicate the heater geometry.

$$
\bar{T}_{f}=\frac{1}{2}\left(T_{f \text {.in }}+T_{f \text {.out }}\right)
$$




$$
\begin{aligned}
& \bar{T}_{w}=\frac{1}{\mathrm{n}}\left[\sum_{i=1}^{\mathrm{n}} T_{w i}\right] \\
& T_{w i}=T_{i}-\frac{2.5 q}{1000 \lambda_{s}}
\end{aligned}
$$

Where $\bar{T}_{f \text {.in }}$ is the inlet temperature, $\bar{T}_{f \text {.out }}$ is the outlet temperature.

The average Nusselt number and the friction factor are calculated by the inner diameter of the test tube. The Nusselt number in terms of average heat transfer coefficient is defined in eq. 5 .

$$
N u=\frac{\alpha D}{\lambda}
$$

The Reynolds number is defined in eq. 6 .

$$
\operatorname{Re}=\frac{\rho u D}{\mu}
$$

The pressure loss of the test tube, $\Delta \mathrm{p}$, is defined in the non-dimensional form by eq. 7 .

$$
f=\frac{\Delta P}{\left(\frac{L}{D}\right)\left(\rho \frac{u^{2}}{2}\right)}
$$

Where $\mathrm{u}$ is the mean velocity in the test tube, and $\mathrm{L}$ is the test tube length. Apparent friction factors are based on the isothermal condition or without heating condition. All of the thermo-physical properties of air were determined at the overall bulk air temperature.

\section{Results and discussion}

\subsection{Influence of twist ratio}

The relationship between Nusselt number, friction factor and Reynolds number are given in Fig. 3 and 4 respectively. In Fig. 3, four types of twist ratio as well as the liquid-solid two phase data are involved. The Nusselt number increases as Reynolds number increases. The heat transfer rate of Kenics static mixer is higher than the liquid-solid two phase flow that may be caused by the strong swirl flow in the Kenics static mixer. It can conclude that the combination of fluid of wall and center regions, which were generated by centrifugal force, tangential velocity component and smaller flow cross-sectional area, would enhance the heat transfer significantly.

It is also found that the heat transfer rate increases as the twist ratio increases. The reason would be that the turbulent intensity and flow length obtained from higher twist ratio are lower than those generated at higher ratio (PR). The average Nusselt numbers for the enhancement devices with $\mathrm{PR}=1.5,2.0,2.5$ and 3.5 are $179 \%$ and $143 \%$ respectively, which are better than these generated in the liquid-solid two phase flow.

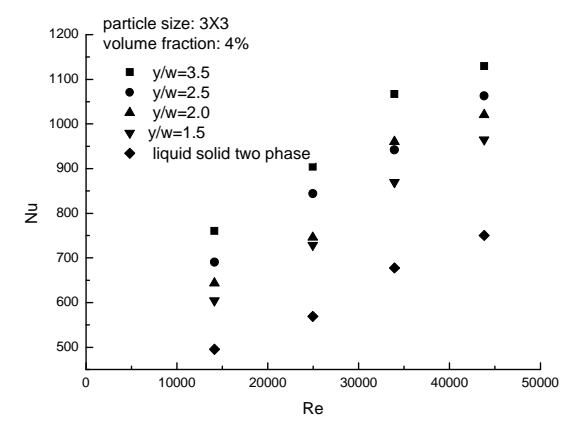

Fig. 3 Effect of twist ratio on heat transfer enhancement.

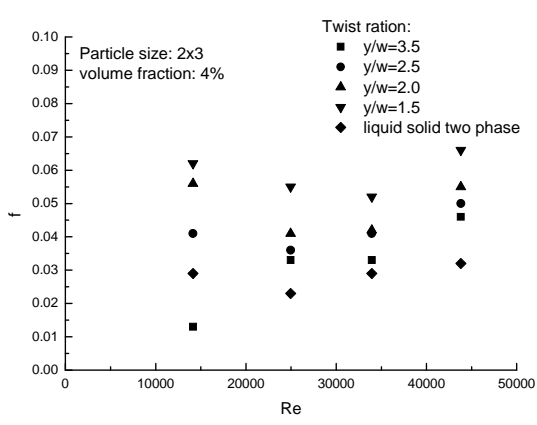

Fig. 4 Effect of twist ratio on friction factor.

In Fig.4, the friction factor obtained from the tube with Kenics static mixer is significantly higher than that generated without Kenics static mixer. Moreover, the result indicates that use of smaller 
twist ratio may lead to the higher friction factor since the stronger swirl could be generated by the shorter pitch length $(\mathrm{y})$ which would lead to the higher tangential contact between the swirling flow and the tube surface. Therefore, the Kenics static mixer with $\mathrm{PR}=1.5$ performed the maximum friction factor while the $\mathrm{PR}=3.5$ had the minimum friction factor.

This indicates that the reverse flow and boundary layer disruption would enhance the convection heat and momentum processes. The reverse turbulence flow region could improve the convection so that it may help to increase the effective axial Reynolds number. In order to maintain the throughput, the cross-sectional area of flow needs to reduce, and this would result in increasing mean velocity and temperature gradients which would produce higher flux of heat and momentum caused by the larger effective driving potential. On the other hand, the boundary layer eruption would cause the global mixing between the core and wall regions, thus it may enhance the convective process. Given the experimental conditions, the average Nusselt number of Kenics static mixer is $160 \%$ over the Nusselt number of non Kenics static mixer. However, increasing the heat transfer rates may cause the high pressure loss.

\subsection{Influence of solid volume fraction}

The relationship between the Nusselt number, friction factor and Reynolds number with respect to the four different solid volume fractions are presented in Fig. 5 and 6. Fig. 5 shows the effect of solid volume fraction on the dependence of Nusselt number with different Reynolds number. Each solid volume fraction performs the similar enhancement trends regarding to the Reynolds number. The heat transfer enhancement increases as the Reynolds number increases. The large particle diameter would produce the large heat transfer enhancement is. In addition, under the same Reynolds number, the large solid volume fraction would cause big difference in heat transfer enhancement.

Fig. 6 presents the friction factor versus Reynolds number in the tube with different solid volume fractions. The friction factor increases as the volume fraction increases, but the effect is not obvious for the higher Reynolds number.

Based on the experimental data, the tube-side heat transfer coefficient and pressure drop are functions of Nusselt number and friction factor. The correlations are represented as heat transfer coefficient and friction factor given in eq. 8 and eq. 9 respectively.

$$
N u=0.6065 \operatorname{Re}^{0.6967} P R^{0.161} V_{m}^{0.0169}
$$

where $14,000 \leq \operatorname{Re} \leq 45,000, \operatorname{Pr}>3,1 . .5 \leq \mathrm{y} / \mathrm{w} \leq 3.5$

$$
f=0.0111 \operatorname{Re}^{0.0665} P R^{-0.0002} V_{m}^{-0.0008}
$$

where $14,000 \leq \operatorname{Re} \leq 45,000, \operatorname{Pr}>3,1.5 \leq \mathrm{y} / \mathrm{w} \leq 3.5$

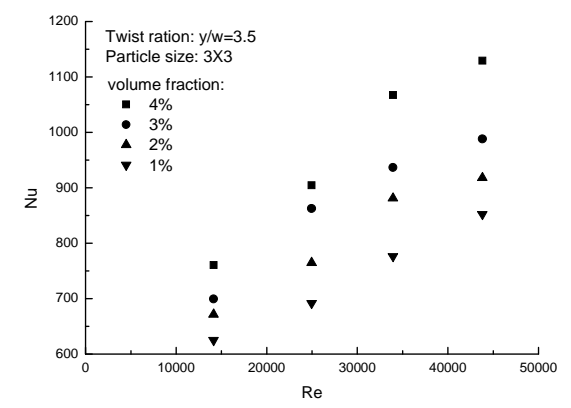

Fig. 5 Effect of particle volumetric concentrations on heat transfer enhancement.

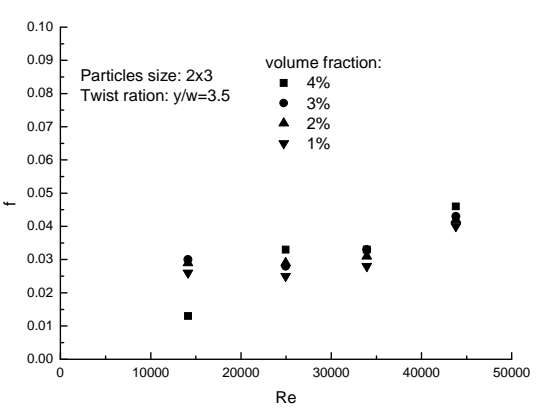

Fig. 6 Effect of particle volumetric concetrations Effect of particle volumetric concetrations on friction factor 


\section{Conclusion}

The heat transfer and friction factor in horizontal liquid-solid fluidized bed heat exchanger with a Kenics static mixer are investigated with respect to the Reynolds numbers ranging from 14,000 to 45,000 . The effects of different twist ratios and volume fractions on heat transfer enhancement are also studied. The conclusions are described as follows:

(1) The Nusselt number and friction factor have positive correlation with Reynolds number. Comparing with the liquid-solid two phase flow, the Kenics static mixer would perform higher heat transfer rate.

(2) The heat transfer rate increases as the twist ratio increases. However, the friction factor decreases as the twist ratio increases. The heat transfer rate of the Kenics static mixer is higher than that of the liquid-solid two phase flow up to $53 \%, 39 \%, 30 \%$ and $22 \%$ regarding to $\mathrm{PR}=3.5,2.5,2.0$ and 1.5 , respectively.

(3) The heat transfer rate and friction factor increase as the solid volume fraction increases, but it would not be significant at higher Reynolds number.

\section{Acknowledgements}

This work was financially supported by the Hebei Province Natural Science Foundation (D2014202074) and Hebei Province Science and Technology Support Program (14273105D).

\section{References}

[1] Smith Eiamsa-ard, Sarawut Rattanawong, Pongjet Promvonge: International Communications in Heat and Mass Transfer Vol. 357-364 (2009), p. 36

[2] M. Aghajani, H. Muller-Steinhagen, M. Jamialahmadi: International Journal of Heat and Mass Transfer Vol. 317-329 (2005), p. 48

[3] Paisarn Naphon, Tanapon Suchana: International Communications in Heat and Mass Transfer Vol. 236-241 (2011), p. 38

[4] Smith Eiamsa-ard, Chinaruk Thianpong, Pongjet Promvonge: International Communications in Heat and Mass Transfer Vol. 1225-1233 (2006), p. 33

[5] Chinaruk Thianpong, Petpices Eiamsa-ard, Khwanchit Wongcharee, Smith Eiamsa-ard: International Communications in Heat and Mass Transfer Vol. 698-704 (2009), p. 36

[6] Sibel Gunes, Veysel Ozceyhan, Orhan Buyukalaca: Experimental Thermal and Fluid Science Vol. 684-691 (2010), p. 34

[7] P. Murugesan, K. Mayilsamy, S. Suresh: Chinese Journal of Chemical Engineering Vol. 1038-1042 (2010), p. 18

[8] Halit Bas, Veysel Ozceyhan: Experimental Thermal and Fluid Science Vol. 51-58 (2012), p. 41

[9] C. Hudson, C.L. Briens, A. Prakash: Powder Teclmology Vol. 101-113 (1996), p. 89 